\title{
Off-pump CABG and Zamvar pericardial fold
}

\author{
Om Prakash Yadava ${ }^{1}$ [D $\cdot$ Vipin Zamvar ${ }^{2}$
}

Received: 24 August 2018 / Accepted: 24 September 2018 / Published online: 17 October 2018

(C) Indian Association of Cardiovascular-Thoracic Surgeons 2018

\begin{abstract}
This is a free conversation with the originator of the 'Zamvar pericardial fold' on the status of Off Pump Coronary Artery Bypass Surgery. An attached video describes the technique of taking the Lima stitch through the Zamvar's pericardial fold.
\end{abstract}

Keywords Off-pump CABG $\cdot$ Zamvar pericardial fold $\cdot$ Lima sitich

Dr. Zamvar feels that both pump and off-pump techniques of coronary artery bypass surgery $(\mathrm{CABG})$ are equally good for routine surgeries. However, for high-risk cases, off-pump scores over on-pump surgery. He describes the Zamvar pericardial fold for taking the deep pericardial stitch (Lima stitch-Video 1). This fold runs from the superior aspect of left superior pulmonary vein to the lower end of the left inferior pulmonary vein and is formed due to the visceral pericardium taking a double U-turn over the left-sided pulmonary veins before becoming the parietal pericardium [1]. Dr. Zamvar feels that it is not necessary for trainees to do on- pump surgery before doing off-pump CABG. However, it does help to visit various mentors, after a certain degree of proficiency has been achieved to learn the intricate nuances of the procedure.

\section{Reference}

1. Zamvar V. The Zamvar pericardial fold. J Cardiothorac Surg. 2017;12:84.

Electronic supplementary material The online version of this article (https://doi.org/10.1007/s12055-018-0745-9) contains supplementary material, which is available to authorized users.

Om Prakash Yadava

op_yadava@yahoo.com

1 National Heart Institute, New Delhi, India

2 Edinburg, UK 